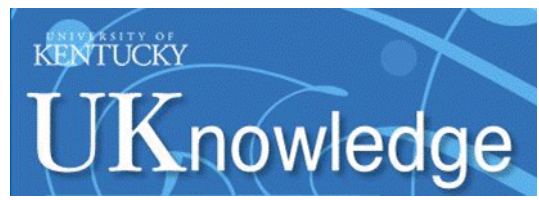

University of Kentucky

UKnowledge

\title{
Incorporating Battery Energy Storage Systems Into Multi-MW Grid Connected PV Systems
}

\author{
Vandana Rallabandi \\ University of Kentucky, vandana.rallabandi@uky.edu \\ Oluwaseun M. Akeyo \\ University of Kentucky, ochichikeyo@gmail.com \\ Nicholas Jewell \\ LG\&E and $K U$ \\ Dan M. Ionel \\ University of Kentucky, dan.ionel@uky.edu
}

Follow this and additional works at: https://uknowledge.uky.edu/peik_facpub

Part of the Power and Energy Commons

Right click to open a feedback form in a new tab to let us know how this document benefits you.

\section{Repository Citation}

Rallabandi, Vandana; Akeyo, Oluwaseun M.; Jewell, Nicholas; and Ionel, Dan M., "Incorporating Battery Energy Storage Systems Into Multi-MW Grid Connected PV Systems" (2019). Power and Energy Institute of Kentucky Faculty Publications. 25.

https://uknowledge.uky.edu/peik_facpub/25

This Article is brought to you for free and open access by the Power and Energy Institute of Kentucky at UKnowledge. It has been accepted for inclusion in Power and Energy Institute of Kentucky Faculty Publications by an authorized administrator of UKnowledge. For more information, please contact UKnowledge@lsv.uky.edu. 


\title{
Incorporating Battery Energy Storage Systems Into Multi-MW Grid Connected PV Systems
}

\author{
Digital Object Identifier (DOI) \\ https://doi.org/10.1109/TIA.2018.2864696
}

\section{Notes/Citation Information}

Published in IEEE Transactions on Industry Applications, v. 55, issue 1.

(C) 2019 IEEE Copyright Notice. "Personal use of this material is permitted. Permission from IEEE must be obtained for all other uses, in any current or future media, including reprinting/republishing this material for advertising or promotional purposes, creating new collective works, for resale or redistribution to servers or lists,or reuse of any copyrighted component of this work in other works."

The document available for download is the authors' manuscript version that is accepted for publication. The final published version is copyrighted by IEEE and available as: V. Rallabandi, O. M. Akeyo, N. Jewell and D. M. Ionel, "Incorporating Battery Energy Storage Systems into Multi-MW Grid Connected PV Systems," in IEEE Transactions on Industry Applications, vol. 55, no. 1, pp. 638-647, Jan.-Feb. 2019. doi:10.1109/TIA.2018.2864696 


\title{
Incorporating Battery Energy Storage Systems into Multi-MW Grid Connected PV Systems
}

\author{
Vandana Rallabandi ${ }^{1}$, Member, IEEE, Akeyo Oluwaseun ${ }^{1}$, Student Member, IEEE, Nicholas Jewell ${ }^{2}$, Senior \\ Member, IEEE, and Dan M. Ionel ${ }^{1}$, Fellow, IEEE \\ ${ }^{1}$ Department of Electrical and Computer Engineering, University of Kentucky, Lexington, KY \\ vandana.rallabandi@uky.edu,m.akeyo@uky.edu,dan.ionel@uky.edu \\ ${ }^{2}$ LG\&E and KU, Louisville, KY Nicholas.Jewell@lge-ku.com
}

\begin{abstract}
The paper analyzes the configuration, design and operation of multi-MW grid connected solar PV systems with practical test cases provided by a 10MW field development. In order to improve the capacity factor, the PV system operates at its maximum power point during periods of lower irradiance, and the power output is limited to a rated value at high irradiance. The proposed configuration also incorporates a utility scale battery energy storage system (BESS) connected to the grid through an independent inverter and benefits of the experience gained with a 1MW 2MWh BESS large demonstrator. The BESS power smoothing and frequency regulation capabilities are illustrated though combined theoretical and experimental studies. The behavior of the grid connected PV and BESS combined system is studied using a modified IEEE 14-bus test system implemented in $\operatorname{PSCAD}^{T M} /$ EMTDC $^{T M}$. The paper also includes a sizing exercise for energy storage in order to provide dispatchable PV power.
\end{abstract}

Index Terms-PV, solar, inverter, BESS, energy storage, battery, ancillary functions, IEEE 14-bus, MPPT, PSCAD, frequency regulation.

\section{INTRODUCTION}

Renewable energy generation is fast developing and solar photovoltaic (PV) systems have surpassed record installations in recent years [1]. Literature on PV related topics includes, for example, techniques for maximum power point tracking (MPPT), which were recently reviewed for example in $[2,3]$, system simulations [4], power electronic circuit topologies for dc-dc converters and inverters [5, 6].

Renewable energy sources are variable in their nature, and energy storage could be used, in principle, for mitigating related issue. Smoothing the PV power output with the aid of battery energy storage systems (BESS) is discussed in literature and the methods include PV ramp rate control, i.e. the BESS charges or discharges when the PV output power ramp rate exceeds preset limits, which may be determined from forecasts of iiradiance data. Other implementations of the power smoothing algorithm include processing of PV power through a low-pass or moving average filter and controlling the BESS to track a power computed based on these values [7-9].

In addition to PV smoothing, ancillary services including frequency and voltage regulation, harmonic compensation, provision of spinning reserves improve operation of the power system, thereby adding further value to storage technologies and also possibly leading to potential deferrals in equipment Authors' manuscript version. The final published version is copyrighted by IEEE and 10.1109/TIA.2018.2864696 (C) 2019 IEEE Copyright Notice. "Personal use of this material is permitted. Permission from IEEE must be obtained for all other uses, in any current or future media, including reprinting/republishing this material for advertising or promotional purposes, creating new collective works, for resale or redistribution to servers or lists, or reuse of any copyrighted component of this work in other works." cost [10]. BESS have been used for multiple functions including energy storage, arbitrage, voltage, and frequency regulation [11-13].

The current paper anaylzes the configuration, design and operation of multi-MW grid connected solar PV systems with practical test cases provided by a 10MW field development and a $1 \mathrm{MW} 2 \mathrm{MWh}$ large BESS demonstrator. The work is an expanded follow-up to a previous conference paper by the group of authors [14]. Contributions include methods for optimal design and control of PV modules and BESS and for the systematic study of power system interactions.

The PV system under study is divided into modular sections, each connected to the grid through its own inverter and transformer, as described in the second section of the paper. Sections III and IV discuss the control of the grid connected inverters in order to achieve operation of the PV arrays at the maximum power point or constant power, depending on the level of irradiance, and include simulations results that are backed by experimental data. Section V deals with the battery energy storage system and its control for PV power smoothing, as well as with the operation of the entire PV and BESS system in a modified IEEE 14 bus test case. Other functions of the BESS such as load frequency regulation, with simulations and measurements are discussed. Section VI includes a sizing study of energy storage systems for dispatchable power in a 10 MW PV farm and the paper concludes in Section VII.

\section{PV System Configuration AND CONTROL}

Multi-MW PV plants are typically divided into several sections [6, 15]. The studied system, which is currently operational on the LG\&E and KU E.W. Brown site, employs ten $1.4 \mathrm{MW}$ solar arrays, each equipped with a $1 \mathrm{MW}$ inverter. A large $1 \mathrm{MW} 2 \mathrm{MWh}$ battery system is also available on site and can be connected as shown in Fig. 1. The configuration includes multiple transformers on the PV and battery side and MPPT controls are directly implemented for the inverters. The power circuit diagram for one modular unit is shown in Fig. 2.

This study employs PSCAD ${ }^{T M} / \mathrm{EMTDC}^{T M}$ as the computational engine. The PV cell model incorporated within this software is based on the Norton equivalent electrical circuit, which consists of a current source connected in parallel with vailable as: V. Rallabandi, O. M. Akeyo, N. Jewell and D. M. Ionel, "Incorporating is permitted. Permission from IEEE must be obtained for all other uses, in any curst 




Fig. 1. Schematic of a practical field implementation for a multi-MW grid tied solar PV system including several modular units connected in parallel. The BESS comprises a battery unit and its associated inverter.

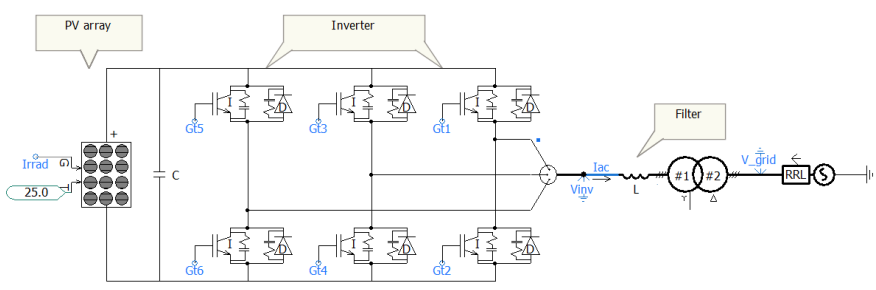

Fig. 2. Power circuit diagram in the PSCAD software for a module comprising a PV array, a 2-level inverter, filter, and a transformer connected to the power grid. Traditional PV systems typically include a dc-dc converter between the PV array and the inverter and use this for MPPT control. In the current implementation, the real power output of the inverter is directly controlled in order to achieve MPPT for the PV array.

a diode with output through shunt and series resistances. The output current ( $i$ ) of the PV cell is given as,

$$
i=i_{g}-i_{o}\left[\exp \left(\frac{V+i R_{s r}}{n \mathrm{~K} T_{c} / q}\right)-1\right]-\left(\frac{V+i R_{s r}}{R_{s h}}\right),
$$

where, $i_{g}$ represents the component of cell current due to photons; $i_{o}$, the saturation current; $\mathrm{K}$, the Boltzmann constant $(\mathrm{K}$ $\left.=1.3810^{-23} \mathrm{j} / \mathrm{K}\right) ; q$, the electron charge $\left(\mathrm{q}=1.6 \times 10^{-19} \mathrm{C}\right)$; $\mathrm{V}$, the output voltage; $T_{c}$, the cell temperature; $R_{s h}$, the shunt resistance and $R_{s r}$, the series resistance. The photo-current $i_{g}$ depends on the amount of solar irradiance incident on the PV cell and its temperature. The photo-current relationship with solar irradiance and cell temperature is given as,

$$
i_{g}=i_{s c R} \frac{G}{G_{R}}\left[1+\alpha_{T}\left(T_{c}-T_{c R}\right)\right],
$$

where, $i_{s c R}$ is the short circuit current at the reference solar radiation and temperature; $G_{R}$, the reference solar radiation; $T_{c R}$, the reference temperature; $G$, the solar irradiance at which current is being calculated; $\alpha_{T}$, the temperature coefficient of the photo-current, usually $0.0017 \mathrm{~A} / \mathrm{K}$ for Si solar cells and $T_{c}$, the cell temperature. At standard test conditions, $G_{R}$ is $1000 \mathrm{~W} / \mathrm{m}^{2}$ and $T_{c R}, 25^{\circ} \mathrm{C}$. Other standard test conditions include the photovoltaic for utility scale application test condition (PTC) with $G_{R}$ and $T_{c R}$ set at $1000 \mathrm{~W} / \mathrm{m}^{2}$ and $20^{\circ} \mathrm{C}$ respectively.

The saturation current, also known as the "dark-current", is expressed as a function of the cell temperature,

$$
i_{o}=i_{o R}\left(\frac{T_{c}^{3}}{T_{c R}^{3}}\right) \exp \left[\left(\frac{1}{T_{c R}}-\frac{1}{T_{c}}\right) \frac{q e_{g}}{n k}\right],
$$

TABLE I

PV CELL AND ARRAY MODULE SPECIFICATIONS.

\begin{tabular}{cc} 
Parameters & Value \\
\hline Cell open circuit voltage(V) & 1.17 \\
Cell short circuit current (A) & 4.01 \\
Cell saturation current $(\mathrm{kA})$ & $1 \mathrm{e}-12$ \\
Temperature coefficient of $i_{g}$ & 0.001 \\
Series resistance per cell $(\Omega)$ & 0.02 \\
Shunt resistance per cell $(\Omega)$ & 1000 \\
Module open circuit voltage(V) & 46.75 \\
Module short circuit current(A) & 9.02 \\
Voltage at MPP (V) & 37.40 \\
Current at MPP $(\mathrm{A})$ & 8.50 \\
Maximum power(W) & 316.50 \\
\hline
\end{tabular}

where, $i_{O R}$ is the saturation current at the reference temperature; $e_{g}$, the band gap energy of the solar cell material and $n$, the diode ideal factor, typically 1.3 for silicon solar cells.

In order to meet power electronics conditioning requirements, PV modules are typically connected in series and parallel to form an array. In the system under study, the PV array is made up of 19 modules connected in series and 236 module strings in parallel. Each module, based on manufacturers' data, has an open circuit voltage of $46.75 \mathrm{~V}$ and short circuit current of 9.02A. The PV cell and module specifications standard test conditions are given in Table I.

The maximum power that can be delivered by a PV array is primarily dependent on the amount of solar irradiance available and its cell temperature. Since these factors tend to vary over time, there is need to incorporate an algorithm to determine the maximum power point (MPP) for a given irradiance and temperature condition. The incremental conductance $(\mathrm{InC})$ and pertub and observe $(\mathrm{P} \& \mathrm{O})$ methods are the most widely used algorithms for MPPT. The $\mathrm{P} \& \mathrm{O}$ method measures the terminal voltage and current of the PV array, perturbs the voltage by adding small disturbances, and observes the change in power. If the perturbation is large, the MPP is determined faster at the expense of accuracy, thus trade offs exist between accuracy and dynamic response.

Furthermore, the $\mathrm{P} \& \mathrm{O}$ method introduces an oscillation in the steady state operation and may fail under conditions of rapidly varying solar irradiance. The $\mathrm{InC}$ method, designed to overcome the drawbacks of the $\mathrm{P} \& \mathrm{O}$ by constantly observing the power-voltage characteristics of the PV system, is used in this paper due to its ability to rapidly and more accurately track the MPP under varying irradiance variations [16].

\section{GRID-CONNECTED INVERTERS}

Different methods can be used to ensure that the PV array operates at its MPP, depending on the configuration of the system. While small PV systems rated for a few $\mathrm{kW}$ can perform MPPT at module, string and central levels without significant cost implications, multi-MW PV systems typically perform MPPT at array levels.

The PV arrays may be connected through a dc-dc converter, typically boost type and an inverter to the grid. In such a 2stage configuration, the dc-dc converter is used for MPPT, and the inverter for grid interconnection. Boosting the PV voltage may eliminate the need to interconnect several modules in 
series, which could lead to singificant loss in power output in case of shading. It might also faciliate elimination of a transformer between the inverter and the grid, and additionally more effective MPPT may be achieved [17].

This study explores the operation of the LG\&E and KU E.W. Brown system, which employs the inverter for both MPPT and grid interfacing. The LGE\&E facility includes 10Freesun FS1050CU-24299T 1MW 2-level inverters, capable of operating with input voltage variations between $700 \mathrm{~V}-1000 \mathrm{~V}$, power curtailment capability from $0-100 \%$ at $0.1 \%$ steps, and an IEEE 1547 utility interconnect with interactive control functions. In such a single stage system, the PV voltage equals the inverter dc-link voltage [18]. Unbalance between the real power input and output leads to variations in this voltage.

Alignment of the reference frame along the grid voltage results in zero quadrature $(q)$ axis grid voltage. Thus, the real power and reactive power can be controlled by controlling the direct $(d)$ and $q$ axes grid current components respectively as seen in the following,

$$
\begin{aligned}
P_{g} & =\frac{3}{2} V_{g d} i_{d}, \\
Q_{g} & =\frac{3}{2} V_{g d} i_{q},
\end{aligned}
$$

where, $P_{g}$ and $Q_{g}$ are the grid real and reactive powers, respectively; $V_{g d}$, the $d$-axis component of the grid voltage, and $i_{d}, i_{q}$, the $d$ and $q$ axis grid current components respectively. The inverter voltages required for this operation are given by,

$$
\begin{aligned}
& V_{d}^{*}=V_{d}^{\prime}+\left(V_{g d}-\omega_{e} L_{g} i_{q}\right), \\
& V_{q}^{*}=V_{q}^{\prime}+\left(V_{g q}+\omega_{e} L_{g} i_{d}\right),
\end{aligned}
$$

where,

$$
\begin{aligned}
& V_{d}^{\prime}=R_{g} i_{d}+L_{g} \frac{\mathrm{d} i_{d}}{\mathrm{~d} t}, \\
& V_{q}^{\prime}=R_{g} i_{q}+L_{g} \frac{\mathrm{d} i_{q}}{\mathrm{~d} t},
\end{aligned}
$$

where, $V_{d}^{*}$ and $V_{q}^{*}$ are the $d$ and $q$ axes components of the inverter reference voltage respectively, $\omega_{e}$, the grid angular frequency and $L_{g}$ and $R_{g}$, the inductance and resistance between inverter and grid respectively. The reference real or $d$-axis component of current is derived from an outer dc-link voltage controller, which maintains this voltage at a set-point obtained from execution of the InC MPPT algorithm. The reactive current reference, is maintained at zero in this study for unity power factor operation of the PV inverter, however, in principle, its value can be derived from an outer reactive power controller, as shown in Fig. 3.

In order to maintain the currents at their set references and ensure grid synchronization, grid voltage oriented control, illustrated in Fig. 4, is used. A phase locked loop (PPL) block generates, from grid voltage measurements, the phase angle employed in reference frame transformations to decouple the
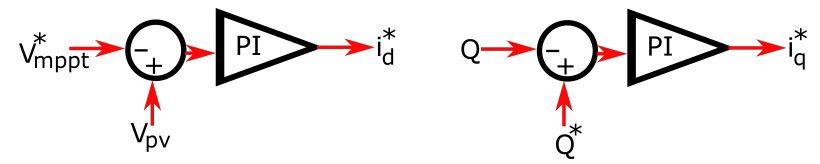

Fig. 3. PV inverter controls for reference current components. Zero current control for $i_{q}^{*}$ ensures unity power factor operation.

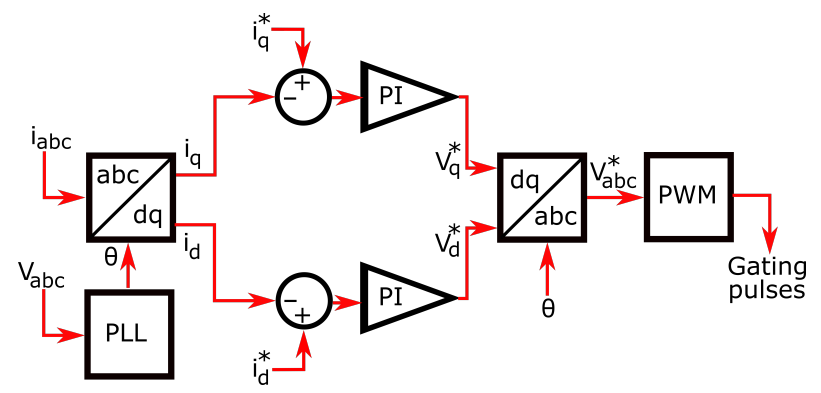

Fig. 4. Inverter control in order to ensure decoupled regulation of active and reactive power components. The grid voltage-oriented reference frame employed for transformations uses the phase angle provided by instantaneous voltage measurements.

3-phase inverter currents into direct and quadrature components, which can be independently tuned to control real and reactive power flow into the grid, respectively.

Simulation studies were conducted on the system of Fig. 2, which employs the inverter for both MPPT and dc-ac conversion. Its performance under different conditions and sudden changes of irradiance was compared with a 2-stage system, which includes a dc-dc converter for MPPT and an inverter for grid interfacing. It was observed that the power outputs of the two systems are closely comparable (Fig. 5).

Using the grid connected inverter for MPPT eliminates the additional cost of acquiring a dc-dc converter rated for the entire PV array power and the loss within the converter. Since irradiance and temperature variations lead to little change in the MPP, and thus the dc-bus voltage, normal operation of the inverter is unaffected by varying conditions. Cases where the inverter cannot be configured to control its dc-link voltage, previously studied by the authors [19], or alternatively, situations with the PV array terminal voltage below requirements, may necessitate an intermediate dc-dc stage.

\section{Constant Power Generation}

Solar PV plants often limit their power output to meet the standards from regulatory bodies concerning PV system capacity factor. In this system, the ratio of PV rating to the power supplied to the grid is about $1.4: 1$. At periods when excess solar energy is available, the panels are made to operate in the constant power mode and MPPT is only implemented at periods of lower irradiance. Each of the ten PV sections, although capable of producing $1.4 \mathrm{MW}$, is controlled to limit its power output to $1 \mathrm{MW}$.

The system is simulated using PSCAD and the results are compared with experimental data gathered from the LG\&E and KU E.W. Brown site over a clear day. This facility includes more than 40,000 fixed tilt solar panels and spans across approximately 45 acres of land and has two weather stations. The 


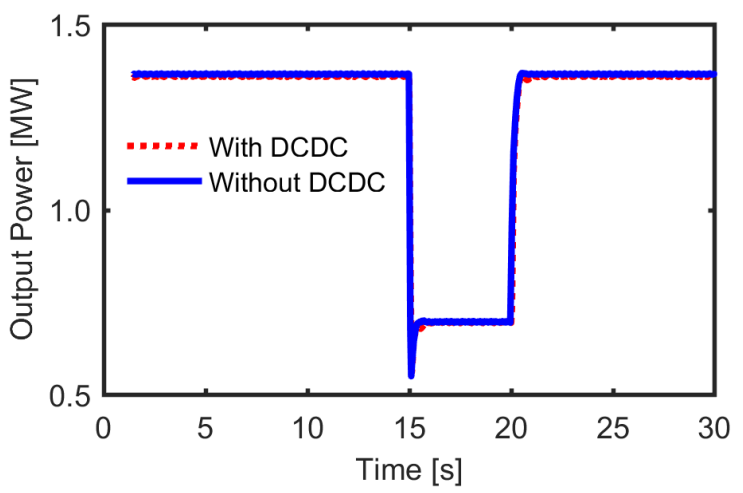

Fig. 5. Variation of the power fed to the grid due to shading of the PV system leading to a drop in irradiance from $1000 \mathrm{~W} / \mathrm{m}^{2}$ to $500 \mathrm{~W} / \mathrm{m}^{2}$. The output powers from systems with and without a dc-dc converter between the PV array and inverter are virtually the same, demonstrating that MPPT is possible for different conditions, even if the dc-dc converter is absent.

average irradiance collected over the two available weather stations $\left(I_{\text {exp }}\right)$ was compared with the ac output power as seen in Fig. 6. Studies with similar irradiance variation, but on an accelerated simulation time scale were conducted and agreement with the experimental measurements, especially at earlier times of the day are observed. Later during the day, however, the simulation predictions of power output are larger than the measurements, and this is attributed to the temperature build-up of the PV modules as well as possible irradiance measurement errors.

With increase in irradiance, the power output increases, until it reaches 0.71 p.u. of the peak power. Following this, the power output of each inverter is limited to $1 \mathrm{MW}$, by imposing saturation limits on the dc-bus voltage controller as seen in Fig. 7. It is seen that the PV array voltage deviates from the MPP value during this period, and only returns to it when the input power to each section falls below $1 \mathrm{MW}$ (Fig. 8). It may be noticed from this figure that working of the PV inverter in the constant power mode causes operating points on the right of the MPP, which could potentially lead to instability. An intermidate dc-dc converter may help mitigate this unstable operation [20]. Two-level inverters typically require a large filter so that the output can meet the required THD standards. A method of reducing the THD of PV systems with twolevel inverters is the adoption of multi-level converters, which produce additional switching levels for the inverter making its output more sinusoidal. Additionally, mutliple PV systems with two-level inverters may be connected in cascaded to achieve multi-level output voltage [21].

\section{Battery Energy Storage Systems (BESS)}

The intermittent behavior of renewable energy limits their large scale grid integration. The output power of a PV system varies with change in the level of irradiance, which is generally not constant throughout the day. Batteries can be used to improve power dispatchability by storing excess energy during peak irradiance and discharging to the grid when the power from the solar energy source is small.

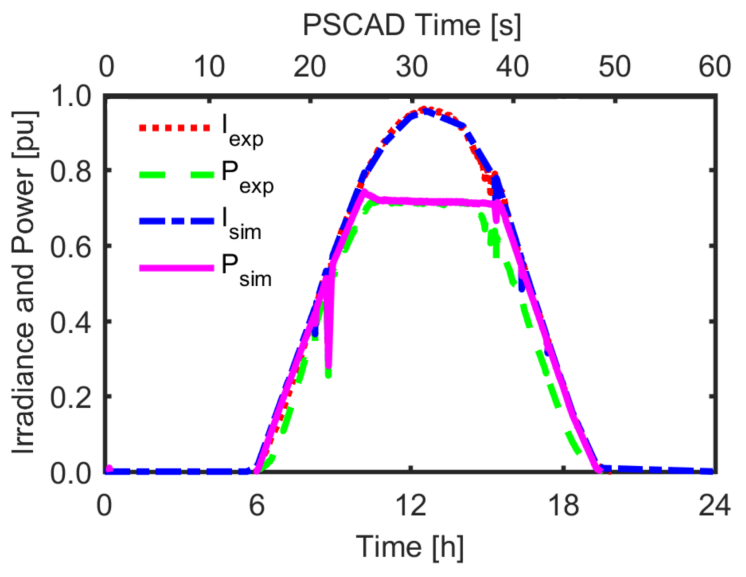

Fig. 6. Experimental and simulated irradiance and PV system output power during a sunny day with sporadic shading. The capacity of the PV plant is purposely limited, i.e. "clipped", to 0.71 p.u. The behavior of the system is simulated by applying a linearly accelerated time frame in PSCAD.

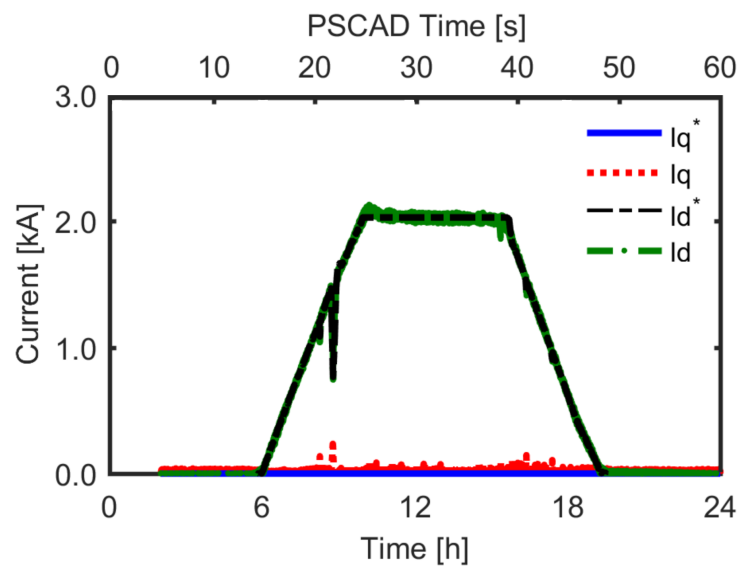

Fig. 7. Current components for the PV inverter. Constant power generation at mid-day is achieved by imposing saturation limits on the outer dc-bus voltage controllers providing the d-axis current reference.

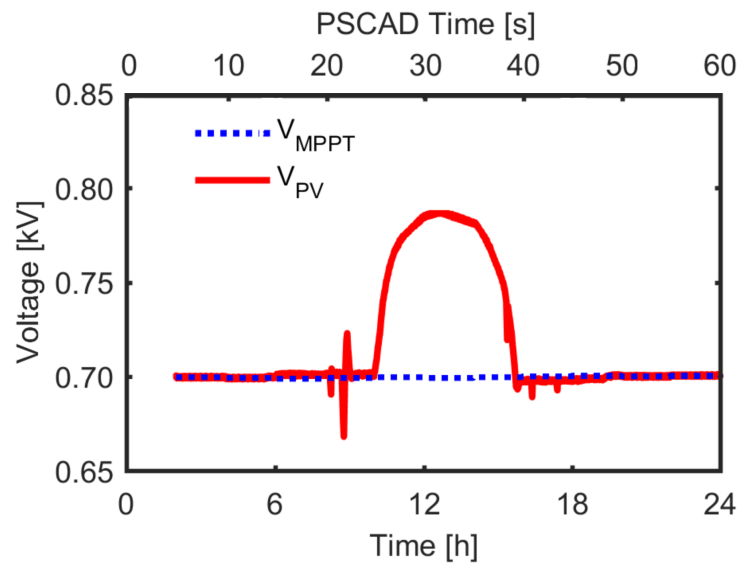

Fig. 8. PV array terminal voltage and its set point determined by the MPPT controller. The inverter is operated in constant power mode at $0.71 \mathrm{p}$.u. when large irradiance values would yield higher PV power output. 
The $1 \mathrm{MW} / 2 \mathrm{MWh}$ energy storage system at LG\&E KU includes a Li-ion battery bank stored in two $6.06 \times 2.44 \times 2.6 \mathrm{~m}$ shipping containers. The battery modules include 28-cells, with 17-modules stacked per rack such that each container has 10-racks. In order to maintain the battery temperature at the required value, the containers are equipped with heating and cooling systems, which maybe energized from the battery.

Each of the LG Chem M48126P3b1 ESS battery modules has a nominal output voltage of $51.8 \mathrm{~V}$ and a capacity of $126 \mathrm{Ah}$. These modules are connected in series and parallel so that the terminal voltage from each container is about $950 \mathrm{Vdc}$ and it is directly connected to the Dynapower CPS$10001 \mathrm{MW}$ inverter. This energy storage inverter can be controlled to perform various functions some of which include; the Autonomous Frequency-Watt Mode, where the system charges or discharges depending on the difference between the measured and reference grid frequencies. The inverter can also be controlled for power smoothing, which instructs the system on dynamically modifying the Watt input or output in response to fast changes in the commanded power.

In the studied system, the BESS includes a battery and an inverter, which is controlled using a grid voltage oriented reference frame, such that the d-axis component of the current controls the active power, and the q-axis component, the reactive power. The d-axis current component is derived from an outer power loop, as described in the following,

$$
i_{d}^{*}=\left(P_{r e f}^{*}-P_{p v}-P_{b a t t}\right) *\left(K_{p 1}+\frac{K_{i 1}}{s}\right),
$$

The controller regulates the battery power such that the sum of the battery and PV powers follows a desired profile, determined, for example from a power smoothing algorithm (Fig. 9). The reactive current is maintained at zero as the BESS system operates in this study, at unity power factor, though in principle, non-zero values can also be used.

\section{A. PV Power Smoothing}

Smoothing of PV power is generally accomplished by controlling the BESS to track the difference between instantaneous and filtered PV powers for which moving average (MA) or low pass filters are employed. With MA filters, the smoothed or filtered power output variation is found as,

$$
P_{o}[i]=P_{p v}[i]-\frac{1}{n} \sum_{j=0}^{n-1} P_{p v}[i+j],
$$

where, $P_{o}$ is the net power to be supplied by the PV and BESS; i, the sampled point; $P_{p v}$, the power of the PV system and $\mathrm{n}$, the number of points in the average.

The sum of the powers supplied by the battery and PV system is the smoothed output. In other words, the battery absorbs and supplies the "power ripple". The power rating of the battery may be found as the maximum difference between the PV and the net powers. The battery, net and PV powers for an irradiance variation on a cloudy day in the LG\& $E$ and KU E.W. Brown facility are shown in Fig. 10. It is observed that the battery needs to supply approximately 0.5 p.u. of the power, but for very short times, indicating that the BESS is

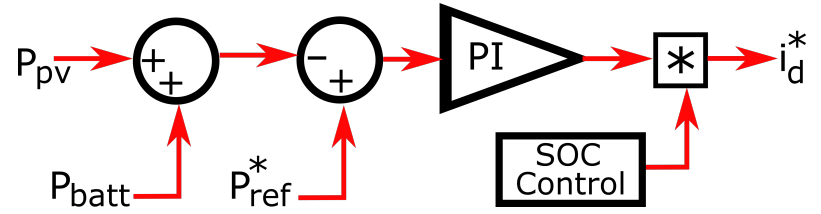

Fig. 9. Control strategy for the BESS ensuring that the PV and battery output powers sum up to a predefined reference value, which is determined depending on the net power to be supplied. The BESS inverter is controlled in order to supply the commanded currents using a grid voltage-oriented reference frame and PWM (not shown). The set power is supplied to the grid provided that the BESS state of charge is within the prescribed limits.

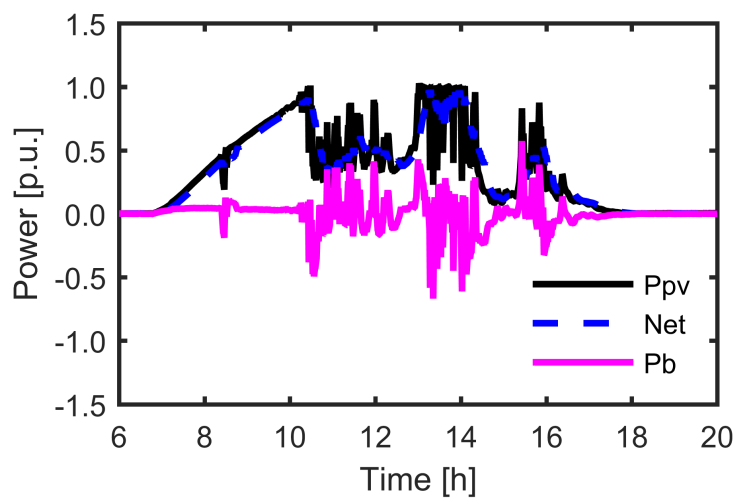

Fig. 10. Power from the PV system using experimental data for a cloudy day. The net power is smoothed using a moving average filter with the BESS controlled in order to track the difference between the net and PV powers.

rated relatively high in terms of power, although a relatively small energy rating may be sufficient for this purpose.

The performance of the PV and BESS system when connected to an IEEE-14 bus system, which represents a portion of the American electric power system in the Midwestern US and is widely accepted by researchers to implement new ideas and concepts in power system engineering related topics such as short circuit analysis, load flow studies, and grid interconnection problems [22] is studied. This system consists of 14 buses, 11 loads and 5 generators of which 3 are synchronous condensers and one slack bus. The Manitoba HVDC research center model of the IEEE 14 bus system in $\mathrm{PSCAD}^{T M} / \mathrm{EMTDC}^{T M}$ was adopted in this study [23].

In the modified IEEE 14 bus system, the 3-phase voltage supply at bus no. 2 is replaced with the designed 10MW PV system connected in parallel with a 100MVA synchronous generator as shown in Fig. 11. With this configuration, the generator, typically operated below its rating, steps up its output power when the PV system integrated with BESS is unavailable due to shading and battery state of charge (SOC) constraints. For the purpose of the study it is considered that the battery's MW rating is enough to provide all of the power, in case of shading of the PV system. Upto $t=4 \mathrm{~s}$, the PV system supplies the power, until it is shaded, when the battery takes over as seen in Fig. 12. The battery can supply the deficit power only for a very short duration of time. At 10s simulation time, the battery's SOC falls below minimum, and it stops supplying power, leading to a transient reduction in the bus frequency before the adjacent synchronous generator steps up 




Fig. 11. Modified IEEE 14 bus system with the PV system incorporating a BESS supplying part of the power at Bus no. 2

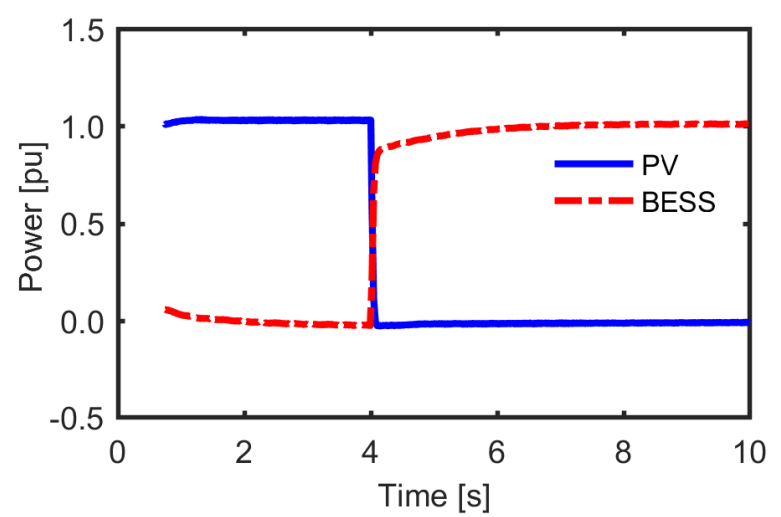

Fig. 12. Transient simulation for a case study in which at $t=4 \mathrm{~s}$ the $\mathrm{PV}$ arrays are completely shaded and its power output is completely compensated with very fast response by the BESS.

its real power output to supply the power deficit from the PV (Fig. 13). In this case, the synchronous generator can supply without significant effect on its operation, the power deficit since it is rated for 100MVA while the PV system is rated for 10MW.

\section{B. Frequency Regulation}

Power smoothing, and compensating for the effect of clouds include short term power supply applications of energy storage

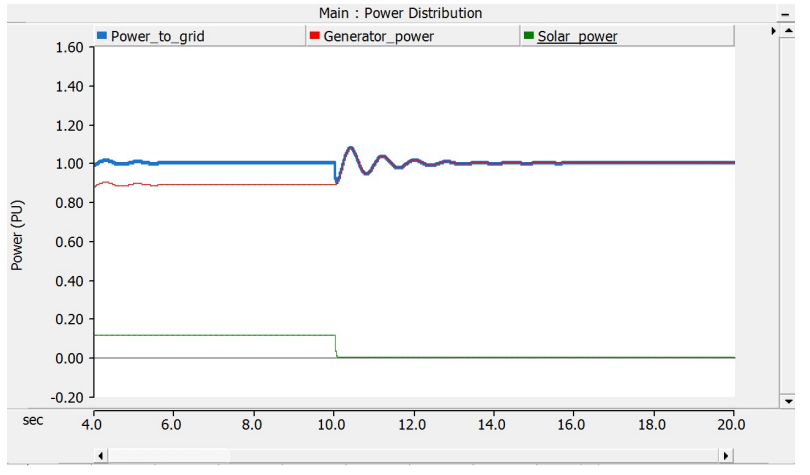

Fig. 13. Transient simulation for the case study illustrating the effect of power loss from both the PV and the BESS $\mathrm{t}=10 \mathrm{~s}$. Until this instance, power at bus no. 2 was supplied by the combined solar power system with $\mathrm{PV}$ and BESS and the synchronous generator. Following the reduction in battery SOC below its minimum value, the synchronous generator supplies the power deficit. Disturbances in power and frequency are observed before the system returns to normal steady state operation.

systems. Another such application is primary frequency regulation, which involves the supply of power for a short duration of time, upto 30s [24, 25]. Power supply and load variations are leading causes of frequency variations. An increase in irradiance or decrease in connected loads leads to higher grid frequency and likewise, lower irradiance or peak load demands lead to a reduction in grid frequency. Battery energy storage systems can be used to regulate utility frequency such that the 


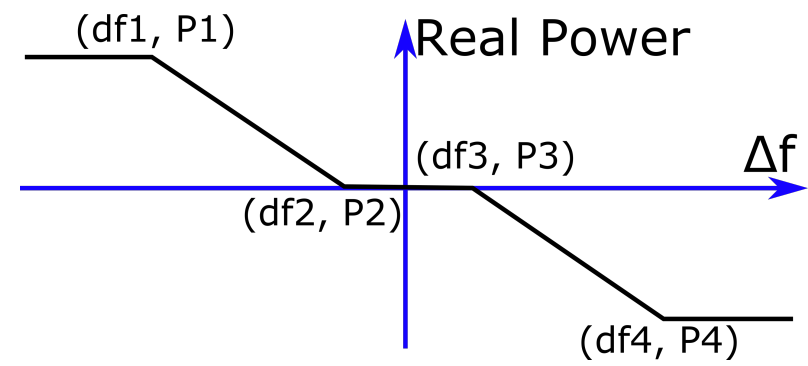

Fig. 14. Droop characteristics for BESS operation with changes in grid frequency. The real power output is limited to the values corresponding to the rated power of the BESS.



Fig. 15. BESS control in frequency regulation mode. The active component of the current, $i_{d}^{*}$, is positive and hence the BESS supplies power when the frequency is below the set point, and current reverses for frequency above this value. The BESS output is maintained at zero when the frequency variation is within $\pm 0.005 \mathrm{~Hz}$.

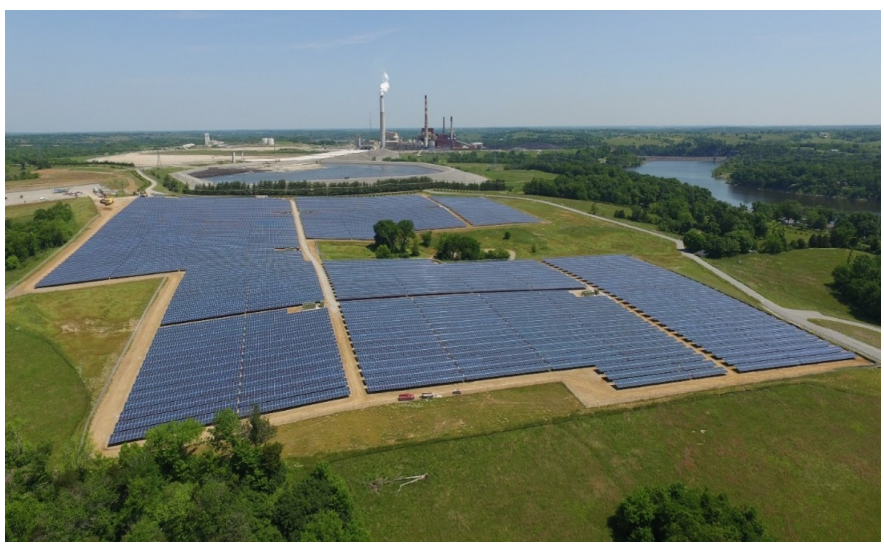

(a)

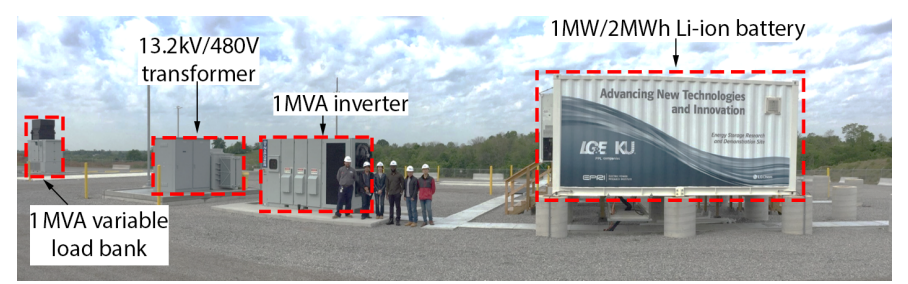

(b)

Fig. 16. The LG\&E and KU 10MW universal solar facility on the E. W. Brown power plant site, which also includes GW rated coal and natural gas fired generators (a) Containers for the $1 \mathrm{MW} 2 \mathrm{MWh}$ battery demonstrator (one shown on the right side of the figure with a second container obscured behind it), BESS inverter (center) and $1 \mathrm{MW}$ controllable load (left). The research site also includes a SCADA facility, which is not shown (b).

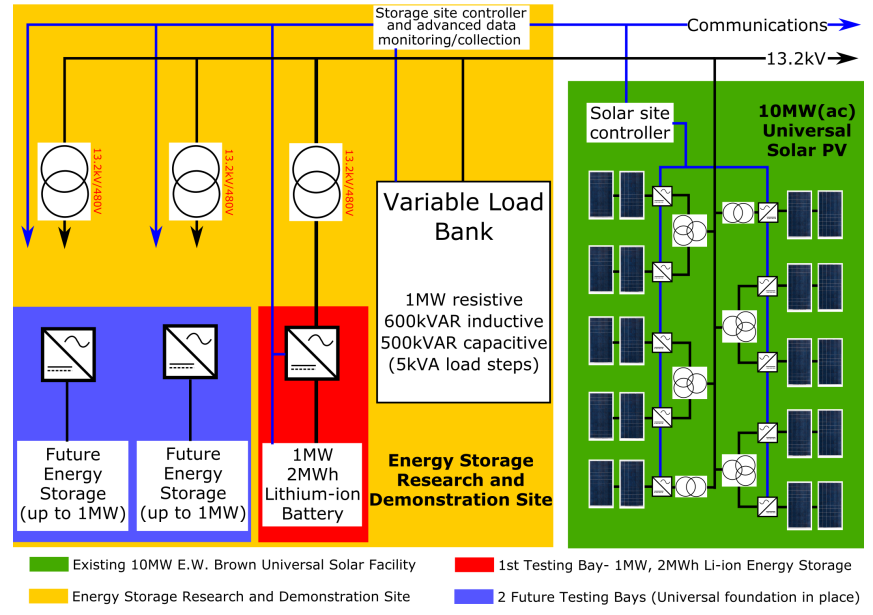

Fig. 17. Schematic diagram for the experimental setup. Two PV inverters are connected to the grid via a single 3-winding 13,200V/390V transformer. All communication data is synchronized with the local data before being uploaded on a private server.

battery charges from the grid when its frequency is above the reference and discharges power to the grid when it is below the reference. The relationship between the frequency change $(\Delta f)$ and power variation $(\Delta P)$ is given as,

$$
\Delta P=P_{r e f}-\beta \Delta f .
$$

The amount of power required to restore the frequency of the grid to its reference value depends on the area frequency characteristics $(\beta)$. For this study, this value is assumed to be constant such that $1 \mathrm{MW}$ power is required for a $0.05 \mathrm{~Hz}$ frequency change, and these droop characteristics, seen in Fig. 14 , can be used to determine the amount of power required to restore grid frequency based on the frequency deviation. The control system for the BESS uses the difference between the reference frequency $\left(f^{*}\right)$ and the actual frequency $(f)$ to determine the reference real power output (Fig 17). In this study, the maximum output of the controller is limited to the power rating of the BESS. The performance of the BESS for frequency regulation was compared with experimental data retrieved from the LG\&E and KU E.W. Brown Universal Solar Facility, pictured along with the $1 \mathrm{MW} / 2 \mathrm{MWh}$ battery energy storage system in Fig. 16. An accelerated frequency variation similar to the experimental data result was applied to the proposed system. It is observed that the BESS output power is positive when the frequency drops below its reference, and it absorbs power when the frequency exceeds $60 \mathrm{~Hz}$ as seen in Fig. 18, in line with experimental measurements, which confirms the successful operation of the BESS for frequency regulation.

\section{On the Feasibility of EnERgy Storage Sizing FOR DISPATCHABLE PV}

In principle, energy storage systems (ESS) may be sized in order to provide constant, $P_{d}$, dispatchable power to the grid. This can be achieved by charging the ESS when the instantaneous power from the PV system exceeds the set value 



Fig. 18. (a) Example of grid frequency variation measured over a couple of hours and simulated on a linearly accelerated PSCAD time frame and (b) BESS output power.

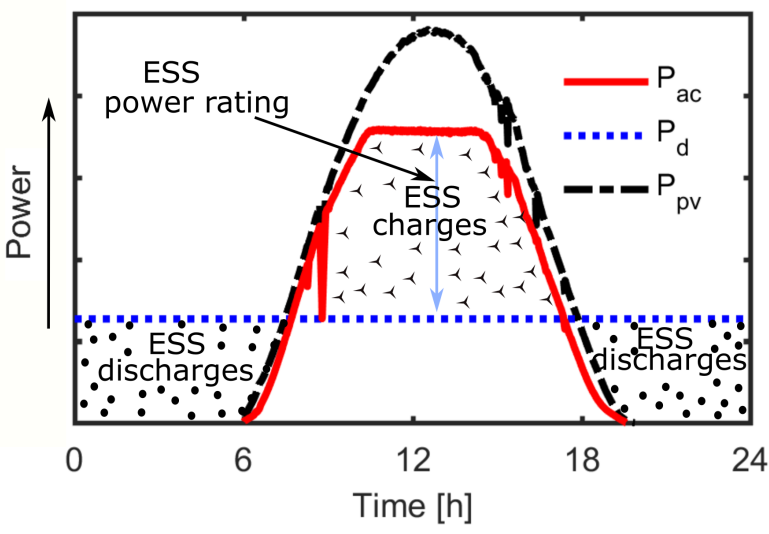

Fig. 19. Schematic illustration of an energy storage sizing method for $24 \mathrm{~h}$ constant power, $P_{d}$, operation. The ESS charges when the power from the PV system exceeds $P_{d}$ and discharges otherwise.

and discharged when required, as illustrated in Fig. 19. The dispatchable power can be defined as

$$
P_{d}=\frac{1}{T} \int_{0}^{T} P_{a c} d t
$$

where, $\mathrm{T}$ is the time period for dispatching, and $P_{a c}$, the output power from the PV:

$$
P_{a c}=\left\{\begin{aligned}
P_{p v} & \text { if } P_{p v}<P_{r} \\
P_{r} & \text { otherwise }
\end{aligned}\right.
$$

where $P_{p v}$ is the maximum available $\mathrm{PV}$ power and $P_{r}$, the rated capacity of the PV plant, which can be "clipped" from the available PV power.

The battery power rating can be obtained as,

$$
P_{b}=P_{r}-P_{d},
$$

and the energy rating as,

$$
E_{b}=\int_{T_{1}}^{T_{2}}\left(P_{a c}-P_{d}\right) d t
$$

where $T_{1}$ is the time corresponding to the positive zero crossing of $P_{a c}-P_{d}$, and $T_{2}$, to the negative zero crossing.

A simple analysis indicates that the larger is the difference between the peak available PV power and the PV plant capacity, the smaller would be the rating for the ESS required to provide constant dispathcable power. Limiting the PV power fed to the grid, an approach that "clips" the power to a constant rated value, could be achieved through a combination of methods, including an MPPT control deviation, as previously discussed, panel reorientation etc, such that the equivalent capcity factor is increased, power fluctuations smoothed out and system reliability enhanced [26].

For the case study considered in this paper with a rated power of 10MW and a good capacity factor for a sunny day the average power for a $24 \mathrm{~h}$ period, which could be constantly dispatched would be 3.6MW. Using the simple analysis previously introduced, this would require an ESS with a rating of $6.5 \mathrm{MW}$ and $36 \mathrm{MWh}$. The relatively high ratio of energy to power, which is also available to a somewhat lower extent in the 1MW $2 \mathrm{MWh}$ demonstrator previously mentioned, is a typical requirement for renewable energy sources that have a relatively low capacity factor. Large ESSS installations employing batteries, such as the 30MW 120MWh Escondido project and the $7.5 \mathrm{MW}, 30 \mathrm{MWh}$ El Cajon development are currently considered in California [27]. As the price of batteries is currently relatively large, BESS technology deployment maybe limited and other ESS systems, such as the innovative pumped hydro solution proposed by Gravity Power [28] may be more feasible.

\section{CONCLUSION}

This paper presented simulation and experimental studies from a 10MW grid connected single stage inverter solar PV system. In the studied configuration, the inverter enables the operation of the PV system at maximum power point for periods of low irradiance, and in constant power mode for irradiance higher that the value that would deliver the set rated power. It was shown that effective MPPT is achieved in the proposed case by using only an inverter, and that an additional dc-dc converter for this purpose is not required, resulting in substantial cost savings.

A BESS, connected to the grid through its own inverter and transformer, is controlled to smooth the power output from the PV system. Computer models of the proposed combined $\mathrm{PV}$ and BESS system have been implemented using as a computational engine the $\mathrm{PSCAD}^{T M} / \mathrm{EMTDC}^{T M}$ software, which is widely used in industrial and utility practice. The results from a modified IEEE 14 bus system illustrate the advantages in terms of transient operation in case of PV shading. 
The BESS can also be used to perform ancillary functions such as grid frequency regulation, where it provides or absorbs the power required in order to maintain the utility frequency at its set value. Simulation and experimental results that show good agreement from a system with a large $1 \mathrm{MW} 2 \mathrm{MWh}$ battery demonstrator are presented.

The paper includes a sizing approach for large energy storage systems in order to provide dispatchable power from multi-MW solar PV plants. The energy ratings are calculated to be high, and, while it may not be yet feasible to use batteries for this purpose, despite current demonstrator and planned developments, other storage technologies, such as pumped hydro storage, may be attractive for the purpose.

\section{ACKNOWLEDGMENT}

The authors thank Dr. David Link of LG\&E and KU and the team of technical experts from Nayak Corp. for their technical advice and contributions. The support of University of Kentucky, the L. Stanley Pigman endowment, Power and Energy Institute of Kentucky (PEIK), and of the LG\&E and $\mathrm{KU}$ utility is gratefully acknowledged.

\section{REFERENCES}

[1] F. Blaabjerg and D. M. Ionel, "Renewable energy devices and systems state-of-the-art technology, research and development, challenges and future trends," Electric Power Components and Systems, vol. 43, no. 12, pp. 1319-1328, 2015.

[2] E. Koutroulis and F. Blaabjerg, "Overview of maximum power point tracking techniques for photovoltaic energy production systems," Electric Power Components and Systems, vol. 43, no. 12, pp. 1329-1351, 2015.

[3] T. Noguchi, S. Togashi, and R. Nakamoto, "Short-current pulsebased maximum-power-point tracking method for multiple photovoltaic-and-converter module system," IEEE Transactions on Industrial Electronics, vol. 49, no. 1, pp. 217-223, Feb 2002.

[4] A. Kalbat, "PSCAD simulation of grid-tied photovoltaic systems and total harmonic distortion analysis," in Electric Power and Energy Conversion Systems (EPECS), 2013 3rd International Conference on, Oct, pp. 1-6.

[5] B. M. T. Ho, S. H. Chung, and S. Y. R. Hui, "An integrated inverter with maximum power tracking for grid-connected pv systems," in Applied Power Electronics Conference and Exposition, 2004. APEC '04. Nineteenth Annual IEEE, vol. 3, pp. 1559-1565 Vol.3.

[6] S. Essakiappan, H. S. Krishnamoorthy, P. Enjeti, R. S. Balog, and S. Ahmed, "Multilevel medium-frequency link inverter for utility scale photovoltaic integration," IEEE Transactions on Power Electronics, vol. 30, no. 7, pp. 3674-3684, July 2015.

[7] A. Ellis, D. Schoenwald, J. Hawkins, S. Willard, and B. Arellano, "PV output smoothing with energy storage," in 2012 38th IEEE Photovoltaic Specialists Conference, June, pp. $001523-$ 001528.

[8] X. Chen, Y. Du, W. Xiao, and S. Lu, "Power ramp-rate control based on power forecasting for PV grid-tied systems with minimum energy storage," in IECON 2017 - 43rd Annual Conference of the IEEE Industrial Electronics Society, Oct 2017, pp. 2647-2652.

[9] C. Ceja-Espinosa and E. Espinosa-Jurez, "Smoothing of photovoltaic power generation using batteries as energy storage," in 2017 IEEE PES Innovative Smart Grid Technologies Conference - Latin America (ISGT Latin America), Sept, pp. 1-6.

[10] D. M. Hart and A. Sarkissian, "Deployment of grid-scale batteries in the united states," unpublished case study prepared for DOE Office of Energy Policy and Strategic Analysis, Washington, DC, 2016.

[11] S. Abdelrazek and S. Kamalasadan, "A novel integrated optimal battery energy management control architecture considering multiple storage functions," in 2014 North American Power Symposium (NAPS), Sept, pp. 1-6.

[12] J. Engels, B. Claessens, and G. Deconinck, "Combined stochastic optimization of frequency control and self-consumption with a battery," IEEE Transactions on Smart Grid, vol. PP, no. 99, pp. 1-1, 2017.

[13] Y. Shi, B. Xu, D. Wang, and B. Zhang, "Using battery storage for peak shaving and frequency regulation: Joint optimization for superlinear gains," 2017.

[14] V. Rallabandi, O. M. Akeyo, and D. M. Ionel, "Modeling of a multi-megawatt grid connected PV system with integrated batteries," in 2016 IEEE International Conference on Renewable Energy Research and Applications (ICRERA), Nov, pp. 11461151.

[15] B. S. Kumar and K. Sudhakar, "Performance evaluation of 10 MW grid connected solar photovoltaic power plant in India," Energy Reports, vol. 1, pp. 184-192, 2015.

[16] D. P. Hohm and M. E. Ropp, "Comparative study of maximum power point tracking algorithms using an experimental, programmable, maximum power point tracking test bed," in Photovoltaic Specialists Conference, 2000. Conference Record of the Twenty-Eighth IEEE, pp. 1699-1702.

[17] J. S. Kim, J. M. Kwon, and B. H. Kwon, "High-efficiency twostage three-level grid-connected photovoltaic inverter," IEEE Transactions on Industrial Electronics, vol. 65, no. 3, pp. 2368 2377, March 2018.

[18] R. Kadri, J. P. Gaubert, and G. Champenois, "An improved maximum power point tracking for photovoltaic grid-connected inverter based on voltage-oriented control," IEEE Transactions on Industrial Electronics, vol. 58, no. 1, pp. 66-75, Jan 2011.

[19] O. M. Akeyo, V. Rallabandi, and D. M. Ionel, "Multi-MW solar PV pumping system with capacity modulation and battery voltage support," in 2017 IEEE International Conference on Renewable Energy Research and Applications (ICRERA), p. 1.

[20] A. Sangwongwanich, Y. Yang, and F. Blaabjerg, "Highperformance constant power generation in grid-connected pv systems," IEEE Transactions on Power Electronics, vol. 31, no. 3, pp. 1822-1825, March 2016.

[21] K. A. Corzine, S. D. Sudhoff, and C. A. Whitcomb, "Performance characteristics of a cascaded two-level converter," IEEE Transactions on Energy Conversion, vol. 14, no. 3, pp. 433-439, Sep 1999.

[22] Power systems test case archive. [Online]. Available: https://www2.ee.washington.edu/research/pstca/

[23] "Ieee 14 bus knowledge base," https://hvdc.ca/, accessed: 201608-03.

[24] D. Greenwood, K. Lim, C. Patsios, P. Lyons, Y. Lim, and P. Taylor, "Frequency response services designed for energy storage," Applied Energy, vol. 203, pp. 115 - 127, 2017.

[25] E. Thorbergsson, V. Knap, M. Swierczynski, D. Stroe, and R. Teodorescu, "Primary frequency regulation with Li-ion battery based energy storage system-evaluation and comparison of different control strategies," in Telecommunications Energy Conference'Smart Power and Efficiency'(INTELEC), Proceedings of 2013 35th International. VDE, 2013, pp. 1-6.

[26] Y. Yang, F. Blaabjerg, and H. Wang, "Constant power generation of photovoltaic systems considering the distributed grid capacity," in IEEE Applied Power Electronics Conference and Exposition - APEC, March 2014, pp. 379-385.

[27] D. Cusick, "Scientific American: Battery storage poised to expand rapidly," https://www.scientificamerican.com/article/battery-storagepoised-to-expand-rapidly/, accessed: 2017-12-27.

[28] "Gravity Power Grid Scale Energy Storage," www.gravitypower.net, accessed: 2017-12-27. 
Vandana Rallabandi (M'17) is a Post-doctoral Researcher in the SPARK Laboratory, Electrical and Computer Engineering Department, University of Kentucky, Lexington, KY. Prior to this, she was a Research Engineer at the General Electric (GE) Global Research Center in Bangalore, India. She obtained the Masters and Ph.D. degrees at the Indian Institute of Technology Bombay, India. She has published over forty journal and conference proceedings papers, including three that received awards from IEEE, IET, and ICRERA, respectively, co-authored four book chapters, and has more than five invention disclosures and patent pending applications. She has been a reviewer for IEEE transactions on Industry Applications, Energy Conversion, Power Electronics, Industrial Electronics and Magnetics, IET Electric Power Applications and Electric Power Components and Systems. Her areas of work include electric machines, power electronics drives, renewable energy devices and systems, energy storage, and power systems.

Oluwaseun Akeyo (S'16) received the B. Eng degree in electrical and electronics engineering from Abubakar Tafawa Balewa University (ATBU), Bauchi, Nigeria and M.S. degree in electrical engineering from the University of Kentucky, Lexington, KY, USA. He is currently working towards the Ph.D. degree at the University of Kentucky, while serving as a research assistant in the SPARK Laboratory and as a teaching assistant in the Electrical and Computer Engineering Department. His research focuses on power systems, power electronics, battery energy storage and renewable energy sources.

Nicholas Jewell (S07-M15-SM18) is a Senior Research Engineer in the Research and Development department at Louisville Gas \& Electric and Kentucky Utilities (LG\&E and $\mathrm{KU}$ ). At LG\&E and $\mathrm{KU}$ his primary responsibility involves collaboration on research projects that contribute in theory, practice and application of new and emerging technologies, processes and equipment related to the energy industry and power markets. Dr. Jewell received his Doctor of Philosophy degree in electrical engineering from the University of Louisville in 2014 and is also a registered Project Management Professional (PMP). He has been author or co-author on a number of industry publications, has received several tech transfer awards from the Electric Power Research Institute, and has 1 patent disclosure. His areas of work include electric power generation, transmission, distribution, energy storage, renewable generation, electric vehicles, process control systems, and network engineering.
Dan M. Ionel (M'91-SM'01-F'13) received the M.Eng. and Ph.D. degrees in electrical engineering from the Polytechnic University of Bucharest, Bucharest, Romania. His doctoral program included a Leverhulme Visiting Fellowship at the University of Bath, Bath, U.K. He was a Post-Doctoral Researcher with the SPEED Laboratory, University of Glasgow, Glasgow, U.K

$\mathrm{He}$ is currently Professor of Electrical Engineering and the L. Stanley Pigman Chair in Power with the University of Kentucky, Lexington, KY, where he also serves as the Director of the Power and Energy Institute of Kentucky (PEIK) and of the SPARK Laboratory. He previously worked in industry, most recently as a Chief Engineer with Regal Beloit, Corp., Grafton, WI, USA, and, before that, as the Chief Scientist for Vestas Wind Turbines. Concurrently, he also was a Visiting and Research Professor at the University of Wisconsin and Marquette University, Milwaukee, WI, USA. He contributed to technology developments with long lasting industrial impact, holds more than thirty patents, and published more than two hundred technical papers, including four that received IEEE awards.

Dr. Ionel was the inaugural Chair of the IEEE Industry Applications Society Renewable and Sustainable Energy Conversion Systems Committee and an Editor of the IEEE TRANSACTIONS ON SUSTAINABLE ENERGY $\mathrm{He}$ is the Editor in-Chief of the Electric Power Components and Systems Journal, the Past Chair of the IEEE Power and Energy Society Electric Motor Subcommittee, and was the General Chair of the IEEE 2017 Anniversary Edition of the International Conference on Electrical Machines and Drives. 